\title{
İvesi koyunlarında besi performansı ve EAAP metoduna göre karkaslarının değerlendirilmesi
}

Fattening performance of Awassi sheep and evaluation of carcasses according to EAAP method

\author{
Sabri GÜL ${ }^{1 / P}$ (iD) Osman BiçER ${ }^{1}$ (D) \\ ${ }^{1}$ Hatay Mustafa Kemal University, Faculty of Agriculture, Department of Animal Science, Antakya-Hatay, Turkey.
}

MAKALE BILGISI / ARTICLE INFO

Makale tarihçesi / Article history:

DOI: $10.37908 /$ mkutbd.606873

Geliş tarihi /Received:19.08.2019

Kabul tarihi/Accepted:12.09.2019

\section{Keywords:}

Awassi sheep, carcass dissection, EAAP.

\footnotetext{
Corresponding author: Sabri GÜL

$\triangle$ : sabrigul@gmail.com
}

\author{
ÖZET / A B S TR A C T
}

Atıf / Citation: Gül S, Biçer O (2020) İvesi koyunlarında besi performansı ve EAAP metoduna göre karkaslarının değerlendirilmesi. MKU. Tar. Bil. Derg. 25(1) : 20-26. DOI: 10.37908/mkutbd.606873

\section{GíRiş}

Dünyanın farklı bölgelerinde yaşayan toplumlar farklı beslenme alışkanlıklarına ve kültürlerine sahiptirler. Ancak her geçen gün insanların kültür seviyesinin yükselmesi ve tüketim alışkanlıklarının değişmesi bir taraftan besin maddesi ihtiyaçlarını artırırken, diğer taraftan dengeli ve sağlıklı beslenme problemlerini ortaya çıkarmaktadır. Dengeli beslenme denilince de ilk akla gelen bireylerin günlük alması gereken bitkisel ve hayvansal protein kaynaklarıdır. Gelişmiş ülkelerde, hayvansal ürünlerin üretimini artırmaya yönelik çalışmalarla birlikte sağlıklı beslenme ve kalite kavramı üzerinde ağırlıkla durulmaya başlanmıştır. Bu durum koyun eti ihtiyacının karşılanmasında yetiştiricilik yanında, çeşitli anatomik kısımların ve dokuların oransal gelişmelerinin de dikkate alınmasını gerektirmektedir.
Tarımsal olarak gelişmiş ülkelerde koyun eti üretimi söz konusu olduğunda genel olarak toklu ve kuzu eti anlaşılmaktadır (Biçer, 1988; Tekel ve ark., 2007). Ülkemizde de yem kaynakları, çayır-mera alanlarının durumu ve halkın tüketim alışkanlıkları gibi bazı teknik ve sosyal nedenlerden dolayı koyun yetiştiriciliği ve koyun eti tüketimi önemli bir yer tutmakta ve bu alanda çalışmalar yürütülmektedir. Süt veriminin yanında et verimi bakımında da iyi bir performansa sahip olan İvesi koyunu, ülkemizde özellikle Doğu Akdeniz ve Güney Doğu Anadolu bölgelerinde önemli bir kırmızı et üretim kaynağı olarak rol oynamaktadır. Et üretimine önemli katkısı olan bu ırkımız, gerek besi teknikleri ve gerekse karkas özellikleri bakımından çok sayıda çalışmaya konu olmuş ve son 20-25 yılda değişik besi yöntemleri ile farklı çağlardaki besi performansı ve karkas özellikleri üzerinde pek çok çalışmalar yürütülmüştür (Güney ve Biçer, 1986; 
Biçer, 1988; Tekel ve ark., 2007; Esenbuğa et al., 2009; Kaya, 2011; Üstüner et al., 2012; Tüney Bebek ve Keskin, 2018).

Ülkemizde koyun karkas özelliklerinin saptanmasında, değişik karkas parçalama ve değerlendirme yöntemleri kullanılmaktadır (Biçer, 1988; Kor ve ark., 1998; Şireli ve Tekel 2013). Kullanılan bu sistemler içerisinde EAAP (European Association for Animal Production) Standart Yöntemi" ne göre (Fisher and Boer, 1994) değerlendirme yönünde henüz bir çalışma yapılmamıştır. Özellikle Avrupa Birliği'ne $(A B)$ girmesi beklenen ülkemizde bu tip çalışmalara ağırlık verilmesi ve $A B$ ülkelerindeki et pazarında söz sahibi olabilmesi için bu tarz çalışmalara önem vermesi gerekmektedir. Bu sahadaki eksiklikleri az da olsa gidereceği düşünülen bu çalışma ile İvesi toklularının ad-libitum besideki çeşitli besi özellikleri ve karkas kompozisyonu da ortaya konulmuştur.

\section{MATERYAL ve YÖNTEM}

Bu araştırma, Hatay Mustafa Kemal Üniversitesi Ziraat Fakültesi Selam Araştırma ve Uygulama Çiftliğinde yürütülmüştür. Çalışmanın hayvan materyalini, işletmede doğmuş 6 baş saf ìvesi erkek toklu oluşturmuştur. Deneme materyali hayvanlara içeriği Çizelge 1'de verilen rasyon ad-libitum olarak verilmiştir. Çalışmada, hayvanlar bireysel bölmelerde $(1.2 \mathrm{~m} \times 1.2 \mathrm{~m}$ x $1.5 \mathrm{~m}$ ) tutulmuşlar ve canlı ağırlık artışı, günlük yem tüketimi gibi veriler bireysel olarak tespit edilmiştir. Çalışmanın besi süresine yedi günlük rasyon alıştırma döneminden sonra başlanmıştır.

Çizelge 1. Toklu için besisinde kullanılan kesif yem karmasının içeriği*

\begin{tabular}{lccc} 
Yem Hammaddesi & Miktar (\%) & Kcal/kg ME & Ham Protein (\%) \\
\hline Arpa & 25 & 2500 & 10 \\
Kepek & 20 & 2100 & 14 \\
Pamuk tohumu küspesi & 22 & 2300 & 32 \\
Mısır & 30 & 3000 & 9 \\
Tuz-mermer tozu katkısı & 2 & -- & - \\
Vitamin & 1 & $\overline{2451}$ & 15.04 \\
Hesaplama ile bulunan & 100 & &
\end{tabular}

*Karma yem içerisine \% 10 oranında yonca samanı katılmıştır.

Deneme için hazırlanan karma yem, bölmelerin ön kısmında yer alan kovalarda, hayvanlara ad-libitum olarak verilmiş ayrıca hayvanların önündeki su günlük olarak değiştirilmiştir. Yoğun besi 13 hafta (91 gün) sürmüştür. Yem tüketiminin tespiti için, yem günlük olarak tartılmış ve hayvanların önüne sürekli taze yem konulmuştur. Besi başı canlı ağırlığının saptanması için, hayvanlar üç gün arka arkaya aynı saatte ve tok karnına tartılmıştır. Besi süresince gelişimi takip etmek amacı ile hayvanlar haftada bir defa, aynı gün ve saatte olmak üzere, tok karnına $100 \mathrm{~g}$ hassasiyetteki kantar ile tartılmıştır. Çalışma süresince ağıl sürekli ışıklandırılmış ve soğuk günlerde ısıtma sağlanmıştır.
Besi sonunda karkas kompozisyonunu ve karkas özelliklerini belirlemek amacı ile grubu temsil edecek şekilde ortalamaya yakın 4 baş toklu kesilmiştir. Kesimden yaklaşık olarak 12 saat önce hayvanların önünden yem alınarak hayvanlar aç bırakılmışlar ve kesim ağırlığı tespit edilmiştir. Kesimden sonra sıcak karkas, yürek, akciğer, karaciğer, dalak, deri, 4 ayak ve baş ağırlıkları saptanmıştır. Karkaslar $+4{ }^{\circ} \mathrm{C}$ 'de 24 saat süreyle bekletilmişlerdir. Bu süre sonunda soğuk karkas ağırlıkları ve vücut ölçüleri alınan karkaslar Fisher ve Boer (1994)'in bildirmiş olduğu EAAP (European Association for Animal Production) Standart Karkas Parçalama Yöntemi" kullanılarak parçalara ayrılmış ve diseksiyon yapılmıştır (Şekil 1). 


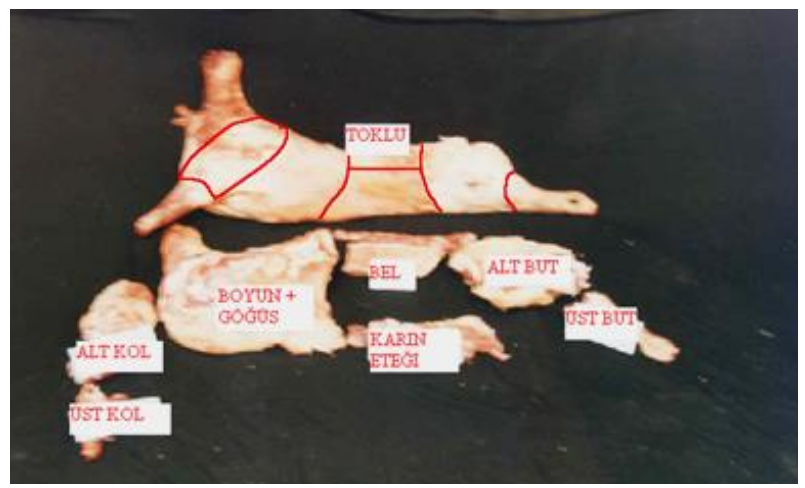

Şekil 1. EAAP Standart Karkas Parçalama Metodu

Çalışmada elde edilen bulgular, SPSS istatistik paket programı kullanılarak analiz edilmiştir (SPSS, 2012).

\section{BULGULAR ve TARTIŞMA}

\section{Besi Özellikleri}

Deneme materyali toklulara ait haftalık canlı ağırlık değişimleri Çizelge 2'de verilmiştir.

Çizelge 2. Haftalık canlı ağırlık değişimi (ortalama \pm standart hata) (kg)

\begin{tabular}{lcc} 
Haftalar & Ağırlık & Günlük ortalama canlı ağırlık kazancı \\
\hline Besi Başı & $34.7 \pm 1.73$ & --- \\
I. hafta & $35.9 \pm 1.66$ & $171.4 \pm 42.50$ \\
II. hafta & $37.2 \pm 1.87$ & $185.7 \pm 42.97$ \\
III. hafta & $38.4 \pm 2.06$ & $171.4 \pm 44.52$ \\
IV. hafta & $39.9 \pm 2.25$ & $214.3 \pm 37.33$ \\
V. hafta & $41.8 \pm 2.20$ & $271.4 \pm 35.19$ \\
VI. hafta & $44.4 \pm 2.14$ & $371.4 \pm 31.52$ \\
VII. hafta & $46.7 \pm 1.90$ & $328.6 \pm 66.67$ \\
VIII. hafta & $48.6 \pm 1.95$ & $271.4 \pm 18.72$ \\
IX. hafta & $51.3 \pm 1.82$ & $385.7 \pm 50.50$ \\
X. hafta & $53.4 \pm 1.77$ & $300.0 \pm 50.36$ \\
XI. hafta & $56.6 \pm 1.79$ & $457.1 \pm 28.20$ \\
XII. hafta & $58.4 \pm 1.96$ & $257.1 \pm 37.98$ \\
Besi sonu & $59.8 \pm 1.84$ & $200.0 \pm 44.37$ \\
\hline & Ortalama & $275.8 \pm 14.60$
\end{tabular}

Çalışmada haftalık canlı ağırlık artışları ile beraber incelendiğinde toklular $34.7 \pm 1.73 \mathrm{~kg}$ ile besiye alınmışlardır. ilk haftaki ortalama canlı ağılık kazancı $171.4 \pm 42.50 \mathrm{~kg}$ olurken bu değer ikinci haftada yükselmiş $(185.7 \pm 42.97 \mathrm{~kg})$ ve 3 . haftaya geçerken yeniden başlangıç canlı ağılık kazancı seviyesine gerilediği görülmüştür. Bu gerileme hayvanların sürekli birlikte büyütülürken bireysel bölmelere alışma sürecinin devam etmesi şeklinde yorumlanabilir. Dördüncü haftadan itibaren tokluklarda günlük canlı ağırlık kazancı yine devam etmeye başlamış 8 . hafta dikkate alınmazsa bu artış 11. haftaya kadar devam etmiştir. Bu haftadan itibaren canlı ağırlık kazancı düşmeye başlamıştır. Bu durumun ise tokluların besisini tamamladığının bir göstergesi olarak kabul edilebilir. Her ne kadar canlı ağırlık artışı devam etse de yemden yararlanma oranı da dikkate alındığında besinin devam ettirilmesinin ekonomik kayıplara yol açacağı söylenebilir. Besi sonu itibariyle 13 haftalık besi sonunda toklularda toplam 25.1 kg'ık canlı ağırlık kazancı görülürken, ortalama $275.8 \pm$ $14.60 \mathrm{~g}^{\prime}$ lık bir canlı ağırlık kazancı hesaplanmıştır.

Üstüner ve ark., (2012) İvesi kuzularında ortalama günlük canlı ağırlık kazancını farklı gruplarda 180.9 ile 287.8 arasında değiştiğini bildirmiştir. Bunun yanı sıra yapmış olduğumuz çalışma, Kul ve Akcan (2002), Esenbuğa et al., (2009), Kaya et al., (2006)'nın bildirişleri ile de uyum içerisinde yer almaktadır.

Deneme süresince hayvanların günlük yem tüketimleri ve yemden yararlanma oranları Çizelge 3'te verilmiştir. 
Çizelge 3. Haftalara göre ortalama günlük yem tüketimi ve yemden yararlanma katsayısı $\left(\overline{\boldsymbol{x}}_{ \pm} \boldsymbol{S}_{\overline{\boldsymbol{x}}, \mathrm{kg})}\right.$

\begin{tabular}{lcc}
\hline Haftalar & Ortalama yem tüketimi $\mathbf{( g )}$ & Yemden yararlanma katsayısı \\
\hline I. hafta & $1727.8 \pm 129.45$ & $10.9 \pm 1.94$ \\
II. hafta & $1651.6 \pm 149.39$ & $8.5 \pm 1.28$ \\
III. hafta & $1854.3 \pm 105.14$ & $12.2 \pm 1.90$ \\
IV hafta & $1861.5 \pm 121.36$ & $8.0 \pm 0.70$ \\
V. hafta & $1927.1 \pm 113.79$ & $5.9 \pm 0.53$ \\
VI. hafta & $1905.1 \pm 100.16$ & $5.1 \pm 0.50$ \\
VII. hafta & $1978.5 \pm 98.49$ & $5.9 \pm 0.64$ \\
VIII. hafta & $1997.0 \pm 101.65$ & $7.1 \pm 0.43$ \\
IX. hafta & $2162.0 \pm 116.23$ & $5.2 \pm 0.38$ \\
X. hafta & $2205.3 \pm 114.32$ & $6.8 \pm 0.82$ \\
XI. hafta & $2333.1 \pm 126.42$ & $7.7 \pm 0.83$ \\
XII. hafta & $2400.3 \pm 142.47$ & $10.4 \pm 2.02$ \\
XIII. hafta & $2477.5 \pm 153.87$ & $15.5 \pm 2.30$ \\
\hline Ortalama & $2067 \pm 51.54$ & $6.4 \pm 0.48$ \\
\hline
\end{tabular}

Besi denemesinde toklularda haftalara göre ortalama yem tüketimleri incelendiğinde 2 . hafta dışında düzenli bir artışın olduğu görülmektedir. İkinci haftadaki düzensizlik canlı ağırlık artışında da görülmüş olup tokluların grup yaşamından bireysel bölmelere uyum sürecinden kaynaklanmış olabileceği söylenebilir. Toklularda 3. haftadan itibaren yem tüketimleri normal seyrinde devam etmiş olup $1727.8 \pm 129.45 \mathrm{~g}$ ile başlayan bu miktar, $2477.5 \pm 153.87 \mathrm{~g}$ ortalama günlük yem tüketimi ile sonlanmıştır. Yemden yararlanma katsayısı dikkate alındığında ilk bir aylık süreç dalgalanma şeklinde sürmüştür. Tokluların yeme ve ortama alışma süresi olarak da değerlendirebilecek bu dönemde, normalin dışında bir yemden yararlanma katsayısı görülmüştür. Beşinci haftadan itibaren 9. haftaya kadar iniş çıkışlı devam eden yemden yararlanma katsayısı beklentiler seviyesinde devam etmiştir. Onuncu ve 11 . haftadaki canlı ağırlık kazancı da dikkate alındığında bu dönemdeki yemden yararlanma katsayıları normal denilebilecek seviyededir. Besinin son iki haftasında, toklularda yem tüketim miktarı ve yemden yararlanma katsayıları yükselirken, günlük canlı ağırlık kazancında ciddi düşüşlerin olduğu görülmektedir. Bu durum besinin 10 veya 11 . haftada bitirilmesi gerektiği şeklide yorumlanabilir. Zira hayvanlarda yem tüketimine istinaden canlı ağırlık kazancı yerine yağlanmanın arttığı da söylenebilir. Tekel ve ark., (2007), İvesi kuzularında 91 günlük besi süresince ortalama günlük yem tüketimini $1.34 \mathrm{~kg}$ olarak bildirmiştir. Hassan ve ark (2013), İvesi kuzularında ortalama yemden yararlanma oranlarını 6.58 ile 8.15 arasında değiştiğini; Kor ve ark., (1998) yine İvesi kuzularında ortalama yemden yararlanma oranlarını 6.5 ile 8.2 arasında değişebileceğini bildirmiştir. Yapmış olduğumuz çalışma yem tüketimi bakımında yüksek, yemden yararlanma oranları bakımından araştırmacıların bildirişleri ile uyum içerisinde olduğu görülmektedir.

\section{Kesim ve Karkas Özellikleri}

Besi süresi sonunda ortalamayı temsil eden toklulara ait ortalama kesim özellikleri Çizelge 4'te verilmiştir.

Çizelge 4.'ten de görüldüğü gibi, toklularda ortalama kesim ağırlığı $57.1 \pm 0.89 \mathrm{~kg}$, kesimden sonra elde edilen sıcak karkas ağırlığı $30.9 \pm 0.06 \mathrm{~kg}$, bu verilerden hesaplanan sıcak karkas randımanı ise \% $54.1 \pm 0.50$, olarak hesaplanmıştır. Kesimden sonra $+4{ }^{\circ} \mathrm{C}$ ' de 24 saat bekletildikten karkaslarda soğuk ağırlıklğı $30.3 \pm 0.59$, soğuk karkas randıman ise \% $54.0 \pm 0.70$ olarak hesaplanmıştır. İvesi kuzularında sıcak ve soğuk karkas randımanını Üstüner ve ark., (2012) \% 48.5 ve \% 47.2; Esenbuğa ve ark., (2009) ise \% 49.14 ve \% 48.15 olarak bildirmişlerdir.

Çizelge 4. Kesim özellikleri $\left(\bar{x}_{ \pm} S_{\bar{x}}\right)$

\begin{tabular}{lc}
\hline Kesim Özellikleri & Ölçümler \\
\hline Kesim Ağırlı̆ı (kg) & $57.1 \pm 0.89$ \\
Sıcak Karkas Ağırlı̆ı (kg) & $30.9 \pm 0.061$ \\
Sıcak Karkas Randımanı (\%) & $54.1 \pm 0.50$ \\
Soğuk karkas ağırlığı (kg) & $30.3 \pm 0.59$ \\
Soğuk karkas randımanı (\%) & $54.0 \pm 0.70$ \\
\hline
\end{tabular}


Elde etmiş olduğumuz bulgular araştırmacıları bildirişlerinden yüksek bulunmuştur. Bunun nedeni çalışma materyali tokluların, kuzulara nazaran daha fazla yağ (özellikle kuyruk yağı) ve kas gelişimine sahip olduğu söylenebilir. Soğuk karkas üzerinden alınan karkasa ait ölçüler Çizelge 5 'te verilmiştir.

Çizelge 5. Soğuk karkastan alınan çeşitli ölçüler $\left(\overline{\boldsymbol{x}}_{ \pm} \boldsymbol{S}_{\bar{x}}, \mathrm{~cm}\right)$

\begin{tabular}{|c|c|}
\hline Özellik & Ölçüler \\
\hline Tüm karkas uzunluğu & $68.1 \pm 0.43$ \\
\hline Yarım karkas uzunluğu & $65.7 \pm 0.52$ \\
\hline But uzunluğu & $22.8 \pm 1.23$ \\
\hline But genişliği & $24.5 \pm 0.37$ \\
\hline But çevresi & $69.2 \pm 0.60$ \\
\hline Göğüs derinliği & $30.2 \pm 0.46$ \\
\hline Kabuk yağı kalınlığı (mm) & $7.1 \pm 0.31$ \\
\hline $\begin{array}{l}\text { Bu çizelgeye göre toklularda tüm karkas uzunluğu } 68.13 \\
\pm 0.43 \mathrm{~cm} \text {, yarım karkas uzunluğu } 65.7 \pm 0.52 \mathrm{~cm} \text { ve but } \\
\text { uzunluğu22.8 } \pm 1.23 \mathrm{~cm} \text { olarak ölçülmüştür. Yine karkas } \\
\text { kalitesini belirleyen önemli bir ölçüt olan ve son kaburga } \\
\text { üzerinde ölçülen kabuk yağı kalınlığı ise } 7.1 \pm 0.31 \mathrm{~mm} \\
\text { olarak tespit edilmiştir. Elde etmiş olduğumuz bulgular } \\
\text { ile Akmaz ve ark., (2000), Tekel ve ark., (2002) ve Shaker }\end{array}$ & $\begin{array}{l}\text { ve ark., }(2002) \text { 'nin İvesi kuzularında karkas ölçüleri ve } \\
\text { kabuk yağı kalınlığı için bildirişleri paralellik } \\
\text { göstermektedir. } \\
\text { Soğuk hava deposunda }+4{ }^{\circ} \mathrm{C}^{\prime} \text { de } 24 \text { saat bekletilen } \\
\text { karkaslara ait kemik, kas ve yağ doku miktarları Çizelge } \\
6^{\prime} \text { da verilmiştir. }\end{array}$ \\
\hline \multicolumn{2}{|l|}{ Çizelge 6. Karkas kompozisyonu $\left(\overline{\boldsymbol{x}} \pm \boldsymbol{S}_{\bar{x}}, \%\right)$} \\
\hline Özellik & Ölçümler \\
\hline Kemik & $16.0 \pm 0.62$ \\
\hline Kas & $49.3 \pm 0.58$ \\
\hline Kabuk yağı & $21.8 \pm 1.60$ \\
\hline Kasarası yağ & $11.2 \pm 0.72$ \\
\hline Atılacak kısım(sinir ve lif) & $1.3 \pm 0.02$ \\
\hline Buharlaşma & $0.4 \pm 0.13$ \\
\hline
\end{tabular}

Karkas kompozisyonu incelendiğinde kemik, kas, kabuk yağı ve kasarası yağ sırası ile $\% 16.0 \pm 0.62, \% 49.3 \pm 0.58$, $\% 21.8 \pm 1.60$ ve $\% 11.2 \pm 0.72$, olarak tespit edilmiştir. Toklularda tespit edilen bu değerler Biçer (1988), Dağ ve Ertuğrul (1993) ve Cengiz (1994)'in bildirişleri ile benzerlik göstermektedir. Karkas parçalarına göre doku kompozisyonu Çizelge 7'de verilmiştir.

Çizelge 7'de görüldüğü gibi koyun karkas parçalarında kas doku miktarı en fazla üst önkol (proximal)'da olduğu görülmektedir. Bu sıralamayı, alt önkol (distal), üst but (proximal), bel, alt but (distal), boyun ve göğüs ile karın eteği olarak izlemektedir.

Sonuç olarak, koyun sayısı bakımından sayısal olarak ilk sıralarda olduğumuz Avrupa Birliği ülkeleri içerisinde et ihracat pazarında yer alabilmemiz için standart bir karkas parçalama sistemine intiyaç duymaktayız. Bu amaçla, İvesi koyunlarında EAAP karkas parçalama yönteminin uygulandığı bu çalışma bir kılavuz niteliğindedir. Bu metodun diğer türlerde de uygulanabilirliği araştırılmalı ve yaygınlaştırılmalıdır. 
Çizelge 7. Koyun karkas parçalarındaki çeşitli dokuların oranları (\%)

\begin{tabular}{|c|c|c|c|c|c|c|c|}
\hline $\begin{array}{l}\text { Alt but } \\
\text { (distal) }\end{array}$ & $\begin{array}{c}\text { Üst but } \\
\text { (proximal) }\end{array}$ & Karın eteği & Bel & $\begin{array}{c}\text { Alt önkol } \\
\text { (distal) }\end{array}$ & $\begin{array}{l}\text { Üst onkol } \\
\text { (proximal) }\end{array}$ & $\begin{array}{c}\text { Boyun ve } \\
\text { Göğüs }\end{array}$ & Karkas Parçal \\
\hline $5.5 \pm 0.21$ & $27.4 \pm 0.40$ & $4.7 \pm 1.00$ & $9.3 \pm 0.3$ & $2.9 \pm 0.30$ & $11.8 \pm 0.40$ & $38.4 \pm 0.70$ & Toplam \\
\hline $29.0 \pm 1.76$ & $10.3 \pm 0.37$ & $0.0 \pm 0.00$ & $13.8 \pm 1.24$ & $31.7 \pm 1.04$ & $15.9 \pm 0.61$ & $19.5 \pm 1.50$ & Kemik \\
\hline $48.0 \pm 2.99$ & $53.9 \pm 1.43$ & $35.2 \pm 3.13$ & $51.8 \pm 2.50$ & $54.0 \pm 1.09$ & $62.7 \pm 0.43$ & $42.4 \pm 0.45$ & Kas \\
\hline $16.5 \pm 3.78$ & $29.0 \pm 3.24$ & $47.0 \pm 7.20$ & $25.7 \pm 2.11$ & $8.2 \pm 0.52$ & $13.3 \pm 0.49$ & $17.5 \pm 2.03$ & Kabuk Yağı \\
\hline $4.3 \pm 0.64$ & $5.9 \pm 0.36$ & $16.1 \pm 5.70$ & $6.5 \pm 0.65$ & $3.7 \pm 0.37$ & $6.9 \pm 0.50$ & $18.5 \pm 0.96$ & Kasarası Yağı \\
\hline $1.5 \pm 0.27$ & $0.5 \pm 0.90$ & $0.7 \pm 0.61$ & $1.1 \pm 0.21$ & $1.3 \pm 0.42$ & $0.7 \pm 0.58$ & $1.7 \pm 0.26$ & Atılacak Kısım \\
\hline $0.7 \pm 1.61$ & $0.4 \pm 0.11$ & $1.0 \pm 0.31$ & $1.10 \pm 0.94$ & $1.10 \pm 0.97$ & $0.50 \pm 0.18$ & $0.4 \pm 0.10$ & Buharlaşma \\
\hline
\end{tabular}

\section{ÖZET}

Amaç: Bu çalışmada, İvesi toklularında besi performansı ve EAAP yöntemine göre karkas özelliklerinin tespiti amaçlanmıştır.

Yöntem ve Bulgular: Çalışmada, toklular bireysel bölmelerde 91 günlük yoğun besiye alınmıştır. Çalışma sonunda elde edilen karkaslar EAAP metoduna göre parçalanmış ve her bir parça için ayrım yapılmıştır. Çalışmada besi başı ve sonu canlı ağırlıkları sırası ile 34.7 $\pm 1.73 \mathrm{~kg}, 59.8 \pm 1.84 \mathrm{~kg}$, beside ortalama günlük canlı ağırlık artışı, ortalama günlük yem tüketimi ve yemden yararlanma oranları sırasıyla $275.8 \pm 14.60 \mathrm{~g}, 2067.1 \pm$ $51.54 \mathrm{~g}, 6.4 \pm 0.48$ olarak hesaplanmıştır.

Genel Yorum: İvesi toklularda uzun süre yapılan besilerde, karkas kalitesi düşmekte ve yemden yararlanma oranı yükselmektedir. Bu durum üretim ekonomikliğini düşürmektedir.

Çalışmanın Önemi ve Etkisi: Ülkemizin kırmızı et ihracatında diğer ülkeler arasında yerini alabilmesi ve koyunlarda standart karkas parçalama için EAAP uygulanabilecek bir yöntemdir.

Anahtar Kelimeler: İvesi koyunu, karkas parçalama, EAAP.

\section{TEŞEKKÜR}

Bu çalışma, Hatay Mustafa Kemal Üniversitesi Bilimsel Araştırma Projeleri Koordinatörlüğü tarafından maddi olarak desteklenmiştir (Proje No: 03 M 1203).

\section{ÇIKAR ÇATIŞMA BEYANI}

Yazar(lar) çalışma konusunda çıkar çatışmasının olmadığı beyan eder.

\section{ARAŞTIRMACILARIN KATKI ORANI BEYANI}

Yazarlar çalışmaya eşit oranda katkı sağlamış olduklarını beyan eder.

\section{KAYNAKLAR}

Akmaz A, Tekin ME, Kadak R, Gürkan M (2000) Alman Siyah Baş x İvesi ve Hampshire Down x İvesi $\left(F_{1}\right.$ ve $\left.G_{1}\right)$ Melezi Erkek kuzuların besi performansı ve Karkas Özellikleri. Turk. J. Vet. Anim. Sci. 24: 17-24.

Aydın K, Keskin M (2018) Muğla ilinde küçükbaş hayvan yetiştiriciliğinin yapısal özellikleri. Mediterr. Agric. Sci. 31: 317-323.

Biçer O (1988) İvesi koyunlarının besi gücü ve karkas özellikleri üzerinde bir araştırma. Çukurova Üniversitesi Fen Bilimleri Enstitüsü, Doktora Tezi, 115 s. Adana.

Cengiz F (1994) Akkaraman, lle de France x Akkaraman $\left(G_{1}\right)$ Melezi ve Anadolu Merinosu kuzularında besi gücü ve karkas özellikleri. Ankara Üniv. Zir. Fak. Yayınları no: 1355, Bilimsel Araştırmalar ve Incelemeler 745, Ankara.

Dağ B, Ertuğrul M (1993) Karayaka ve Border Leicester x Karayaka melezi $\left(F_{1}\right)$ erkek kuzularda besi gücü ve karkas özellikleri üzerinde araştırmalar. Lalahan Hay. Araşt. Enst. Derg. 33: 42-97.

Esenbuğa N, Macit $M$, Karaoğlu M, Aksakal V (2009) Effect of breed on fattening performance, slaughter and meat quality characteristics of Awassi and Morkaraman lambs. Livestock Science 123: 255-260.

Fisher AV, Boer H (1994) The EAAP standart method of sheep carcass assesment. Carcass measurements and dissection procedures report of the EAAP working group on carcass evaluation, in cooperation with the ciheam Instituto Agronomico Mediterraneo of Zaragoza and the $\mathrm{Cec}$ Directorate General for Agriculture in Brussels. Livest. Prod. Sci. 38: 149-159.

Güney O, Biçer O (1986) The fattening performance and carcass characteristics of Awassi $x$ Awassi, lle de France $x$ Awassi (F1) and Chios $x$ Awassi first back cross ram lambs. World Rev. Anim.Prod. 22: 63-67.

Hassan SA, Al-Balati HY, Almosawy JE (2013) Effect of substitution barley by whole dates on performance and digestion of Awassi Lambs. KSÜ Doğa Bil. Derg. 16: 12-15. 
Kaya Ş, Keskin M, Gül S (2006) Effects of Yucca schidigera Extract (Dk 35 powder) on Awassi Lambs performance. J. Anim. Vet. Adv. 5: 57-59.

Kaya \$̧ (2011) The effects of outdoor housing and cafeteria feeding on growth performance and feeding behaviour of Awassi lambs kept in hot climate condition. J. Anim. Adv. 10: 2550-2556.

Kor A, Cedden F, Ertuğrul M, Başpınar E (1998) Sütten kesimde besiye alınan Akkaraman, İvesi x Akkaraman (F1), Sakız x Akkaraman $\left(F_{1}\right)$ erkek kuzularının kesim ve karkas özellikleri. Tar. Bil. Der. 4: 30-38.

Kul S, Akcan A (2002) İvesi ve Ost-Friz x İvesi Melez ( $\left.F_{1}\right)$ kuzularda besi performansı, kesim ve karkas özellikleri. Uludag Univ. J. Fac. Vet. Med. 21: 1-7.

Shaker MM, Abdullah AY, Kridli RT, Blaha J, Sada I, Sovjak $R$ (2002) Fattening performance and carcass value of Awassi lambs, $F_{1}$ crossbreds of Romanov $x$ Awassi and Charollais x Awassi in Jordan. Czech J. Anim. Sci. 47: 429-438.
SPSS. IBM Corp. Released 2012. IBM SPSS Statistics for Windows, Version 21.0. Armonk, NY, USA: IBM Corp. Şireli HD, Tekel N (2013) ìvesi erkek kuzularının besi performansı ve karkas özelliklerine süt emme döneminde farklı büyütme sistemlerinin etkisi. Tar. Bil. Der. 19: 63-70.

Tekel N, Şireli HD, Vural ME (2007) Besi süresinin İvesi erkek kuzuların besi performansı ve karkas özelliklerine etkisi. Tar. Bil. Der. 13: 372-378.

Tüney Bebek D, Keskin M (2018) Mersin ilinde Koyun Yetiştiriciliğinin Mevcut Durumu Bazı Verim ve Yapısal Özellikleri. MKU Ziraat Fakültesi Dergisi 23: 315-323.

Üstüner H, Dikmen S, Türkmen i (2012) Effect of processing on the fattening performance and carcass traits of Awassi ram lambs. Asian J. Anim. Vet. Adv. 7: 1331-1339. 